\title{
COMPARISON OF THE EFFECTS OF EXPLOSIONS INITIATED AT DIFFERENT LOCATIONS IN MULTIPHASE MEDIA: AIR AND STRUCTURE
}

\author{
PETR P. PROCHAZKA \\ Civil Engineering, Czech Technical University in Prague, Czech Republic
}

\begin{abstract}
In connection with the assessment of underground structures, the question arises of the mechanical behavior of the different types of materials of the load-bearing structure exposed to the explosion and the location of its source. This means that the stresses induced by shock waves due to the explosion are in direct relation with the properties of the lining material and the location of the charge. There are a number of numerical methods that deal not only with the issue of shock waves propagation in a closed or semi-closed environment, but also nonlinear properties of the material can be described. In order to feed the numerical procedures with the relevant data, it is essential to carry out practical tests that are best in scale models, saving time and money. Recall that there are means to evaluate the actual behavior of air, structure and surrounding rocks from observation in scale models. This paper focuses on the description of concrete circular tubes simulating the tunnel in the scale of $1 / 20$. The three-phase flow is reduced to two phases (air, structure), for simplicity. The charge is placed on the longitudinal axis and also eccentrically, for comparison. The numerical method is suggested for the completeness of the flow behavior in the multiphase medium. The overpressure exerted on the lining is monitored by sensors that are located directly above the source of the explosion, further on the distal parts of the structure and ultimately overpressure at the mouth of the tube is monitored by the so-called pencil sensor. The source of the explosion is the Semtex 1A explosive in both explosion locations.
\end{abstract}

Keywords: tunnel tubes, different location of charges, different concrete linings, scale models.

\section{INTRODUCTION}

An explosion is a physicochemical process leading to a sudden and very rapid release of energy, a local increase in temperature and pressure, and the degradation of the properties of the environment in which the explosion occurs. The effect of explosion strongly depends on the place, in which it arises, on the shape of structure, which is exposed to the shock waves initiated by the explosion and the material of the structure. First, the description of effects of explosion in an open air is relatively simple, although it may cause also complications if the surface of the structure is irregular (wavy, for example). In this paper, the charge is located in a semi-enclosed space. Second, the location of the charge is either at the longitudinal axis or non-symmetric. The material is always concrete, simple, or reinforced by plastic fibers, or steel fibers.

It is worth noting that the solution of the basic equations describing the flow in certain media and the propagation of the shock waves in reality is quite similar, if solid phase, air or liquid is considered. The principal goal of the most observations in the above field in civil engineering is obtaining the basis for assessment of mechanical behavior of structures, such as plastic behavior or damage. Typically, BLEVE (boiling liquid expanding vapor explosion) occurs when liquid in the vessel is at a temperature above its atmospheric boiling point [1].

Today's civilized world has a very urbanized structure - a large part of the population lives in cities and underground, generally enclosed, spaces, are one of the most important areas of modern towns. However, the structures are very vulnerable to sudden changes in load, associated with terrorist attacks, VBIED, unpredictable explosions (traffic accidents, fire, rapid economic development), etc., that can cause huge damage to structures and may 
have fatal consequences for human lives. Therefore, it is very important to address and anticipate the dynamic effects of explosions in enclosed spaces. The location of the explosive center is very important. It turns out that if its position is on the surface of the building or over the terrain, no follow-up wave and the interaction of the main shock wave with the secondary waves are expected. Another situation occurs when describing the time evolution in closed spaces, where wave interactions play an important role.

Propagation of shock waves in gas (air) that fill underground spaces is described by nonlinear equations of conserving density, momentum and energy. The influence of gas pressure is usually given for adiabatic state for this type of problem. The effects of explosions, i.e. initial airborne shock waves, and then interactions with secondary waves, are calculated for time changes in mass density, motion velocity and changes in internal and kinetic energy. The states of stress and deformation in the structure are also generally described by nonlinear relations.

The issue of the effects of explosions on structures in enclosed spaces is dealt with by a number of publications, [2]-[4], for example. There are a number of publications that lead, if not directly to standards, at least to useful recommendations that come from the findings of practical knowledge [5]-[8].

At present, the most commonly used material for underground structures is concrete, either classic, which is reinforced with steel rods or fiber-reinforced concrete. The latter is characterized by a cement matrix and unevenly distributed and randomly oriented fibers of various materials (synthetic-polypropylene, steel, glass, etc.); the fibers may also have different shapes and sizes. Thanks to these specific properties, such a composite has a higher tensile and shear strength. The abovementioned fibrous materials can be combined, [9], [10]. Steel fibers serve predominantly to bridge cracks in the material, while synthetic fibers increase the ductility and deformability of the concrete. They reduce or even suppress the spalling of concrete. Appropriate application of the free hexagon method may well simulate properties of different types of fiber reinforced concrete.

In order to obtain the material properties of objects subjected to a sudden change in load, tests are carried out which, for more complex problems of the propagation of shock waves in enclosed spaces and their influence on structures are often carried out on physical and scale models [12]-[15]. Compared to $1: 1$ or in situ models make it possible to achieve very reasonable results while saving time, material and energy.

The formulation is based on hydrodynamic nonlinear Euler equations derived from the Landau-Lifschitz theory. This can be reconstructed in cylindrical coordinates, which are introduced in this paper.

\section{MODELS OF TEST SPECIMENS}

Two models were made at a scale of $1 / 30$ with regard to the explanatory value of the experiment and manipulation options. This is a group of five circular tubes which are linked on a half-groove. The tubes have diameters $1 \times 1 \mathrm{~m}^{2}$ (external diameter $\mathrm{x}$ length), thickness $15 \mathrm{~mm}$. Therefore, the total length of the tunnel (made from tubes) was $5 \mathrm{~m}$. Due to the compactness, the tubes were connected by a cement screed near the sensors (Fig. 1).

The goal of this paper is to compare the results from measurements and computations in the above said models. The first concerns the location of the charge at the axis of horizontal symmetry and is studied in details in [16]. The observations following from this paper are here taken for comparison with a new observation, which follows from explosions positioned outside the horizontal axis.

Test specimens of plain concrete are made from class of concrete C 25/30. The test site consists of the individual concrete units and the explosive items are (Fig. 2): 

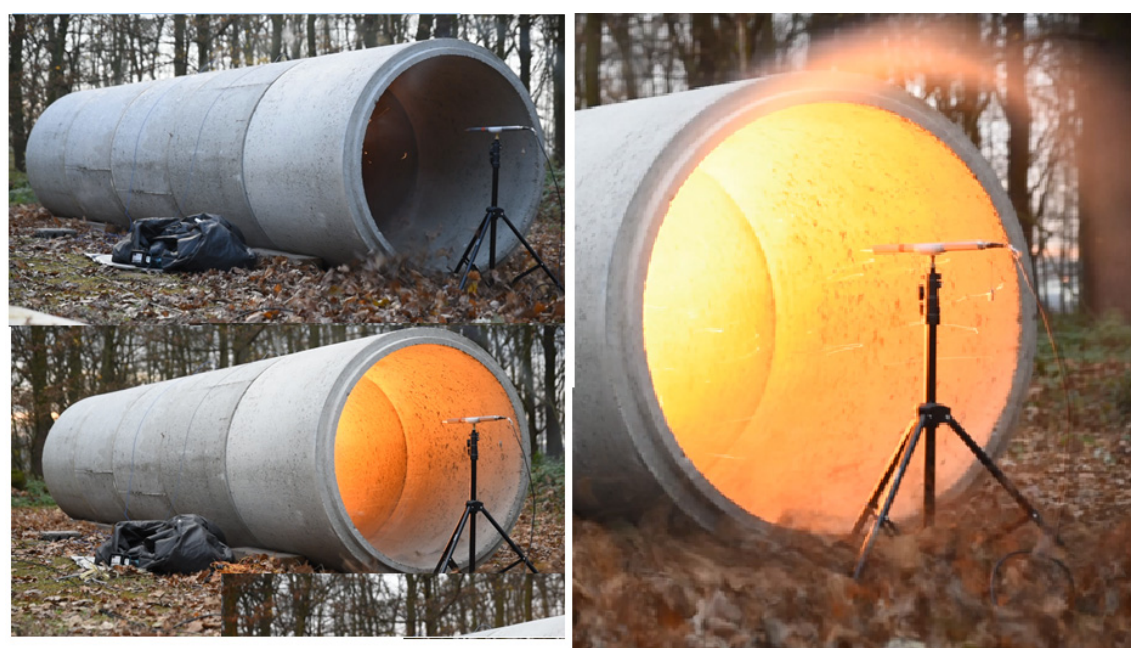

Figure 1: The tubes prepared for the tests and during the test.

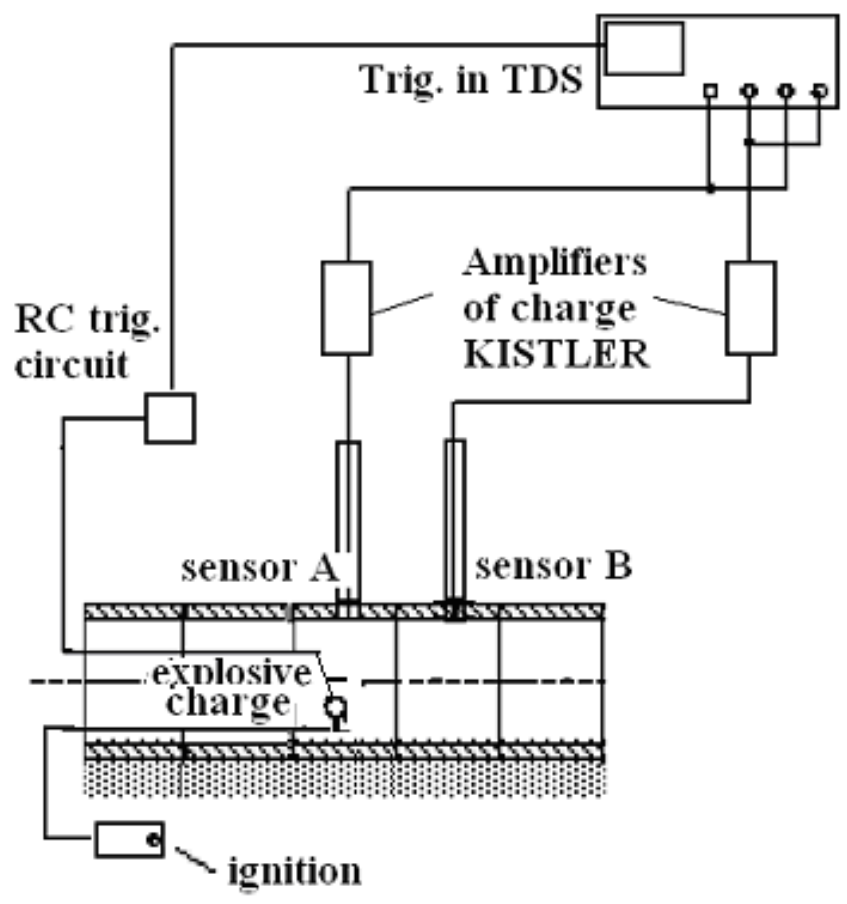

Figure 2: Adjustment of the measurement devices.

- Bulk plastic burst blasting explosives with a nominal mass $m_{X}=20 \mathrm{~g}$ initiated by a SO8 detonator (medium resistance). The detonator is activated by means of a capacitor firing device. 
- A switching sensor is inserted into the charge, which is short-circuited by the pressure and thermal effects of the fumes, which leads to the creation of a synchronization signal in the RC circuit. This pulse triggers the running time of the TDS 3014 synchro.

- The permissible load of a pair of pressure sensors reaches $600 \mathrm{MPa}$, their sensitivity is $1.99 \mathrm{pC} / 100 \mathrm{kPa}$.

- $\quad$ Signals of these sensors are processed using KISTLER 5001 and 5006 amp amplifiers with an upper limit of $170 \mathrm{kc} / \mathrm{s}$. The basic parameter of the amplifier - the ratio of the released hub to the output voltage - was controlled by the calibration unit. In this case, the sensitivity of both transmitters was set to $5 \mathrm{MPa} / \mathrm{V}$.

- The synchro recording logs register the output signals of the transducers at two different sensitivities and at the total signal recording length of $4 \mathrm{~ms}$.

In Fig. 3, locations of sensors are shown.

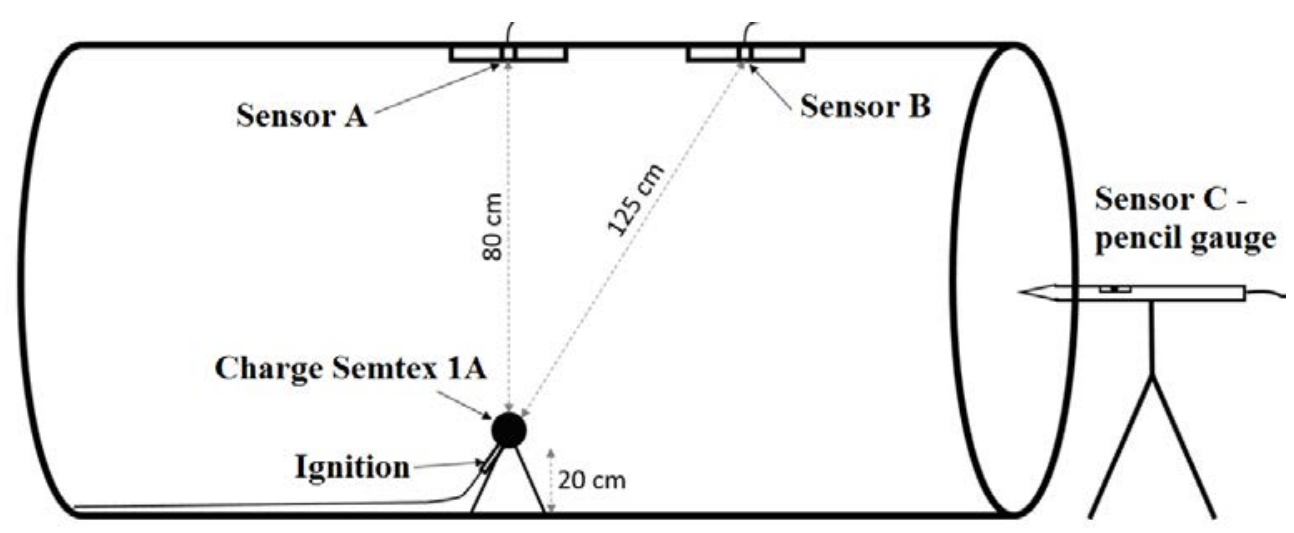

Figure 3: Scheme of the set-up of the explosion and sensors locations, charge location in the non-symmetric charge deposition.

\section{PROCESSING THE EXPERIMENTS}

Two locations of charges were centered inside the tunnel ( $2.5 \mathrm{~m}$ from both open parts). Vertically, the location of the charges was in the first case put in the horizontal axis, and in the second case $20 \mathrm{~cm}$ from the lower part of the tunnel. Two explosions were initiated in each case providing almost the same overpressure spectrum as seen below. The position and the charge itself in our case are shown in Fig. 3.

Sensors $\mathrm{A}$ and $\mathrm{B}$ were placed in a nylon box and the pencil gauge $\mathrm{C}$ are located as seen in Fig. 3.

Semtex 1A plastic explosive of a round shape (Fig. 4), of a nominal weight of $20 \mathrm{~g}$ (similar to the symmetric case [16]), was mounted above the sensor A.

\section{RESULTS FROM EXPERIMENTS}

In order to compare the effects of explosions on the behavior of shock waves and interaction with the structure the case when the charge was positioned symmetrically and nonsymmetrically, the results in the form of overpressure spectra recorded at the sensors A and B are depicted in Figs 5 and 6 (symmetric case) and Figs 7 and 8 in non-symmetric case. In all cases two shots were made for identification of possible discrepancies. 

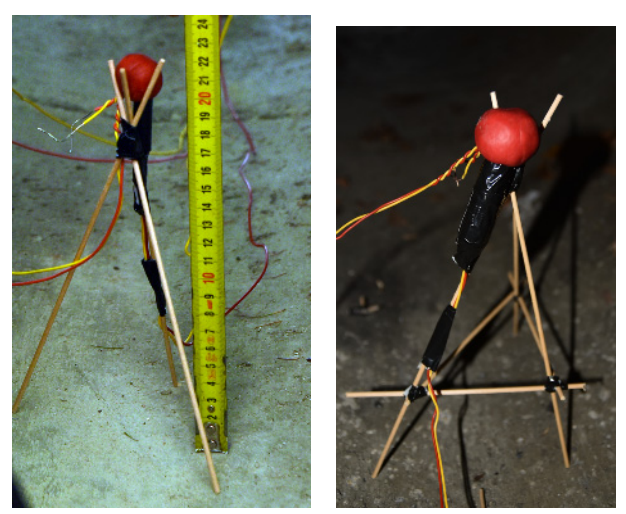

Figure 4: The stand located at the axis of horizontal symmetry (first case) and $20 \mathrm{~cm}$ above the bottom of the tunnel (second case), left stabilized version for the second explosion.

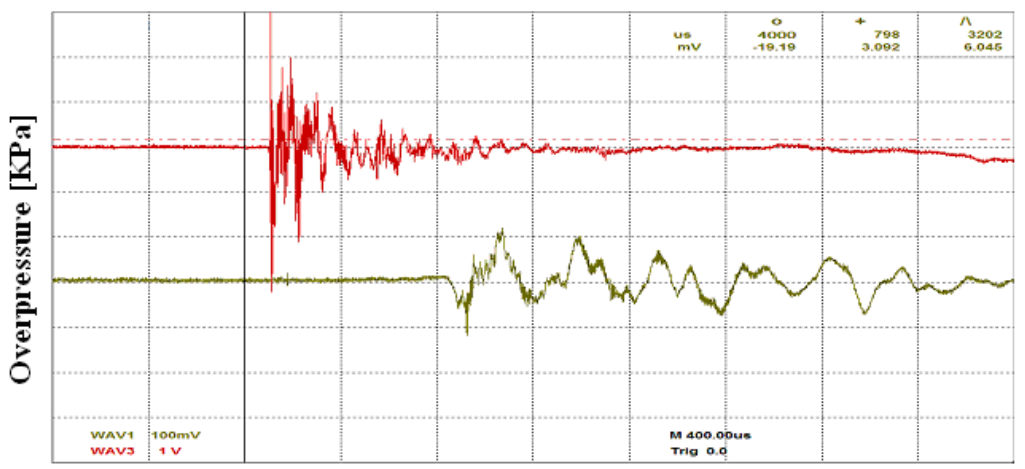

time [ms]

Figure 5: Symmetric position of the charge: first shot.

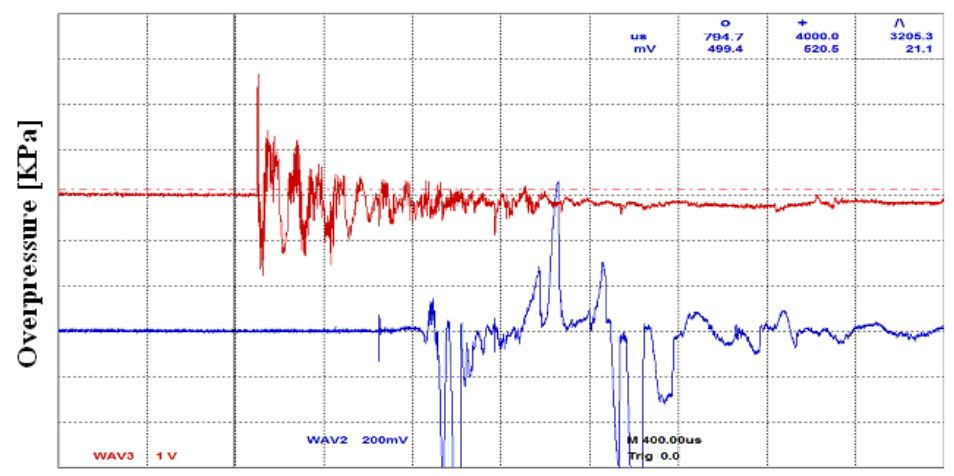

time [ms]

Figure 6: Symmetric position of the charge: second shot. 


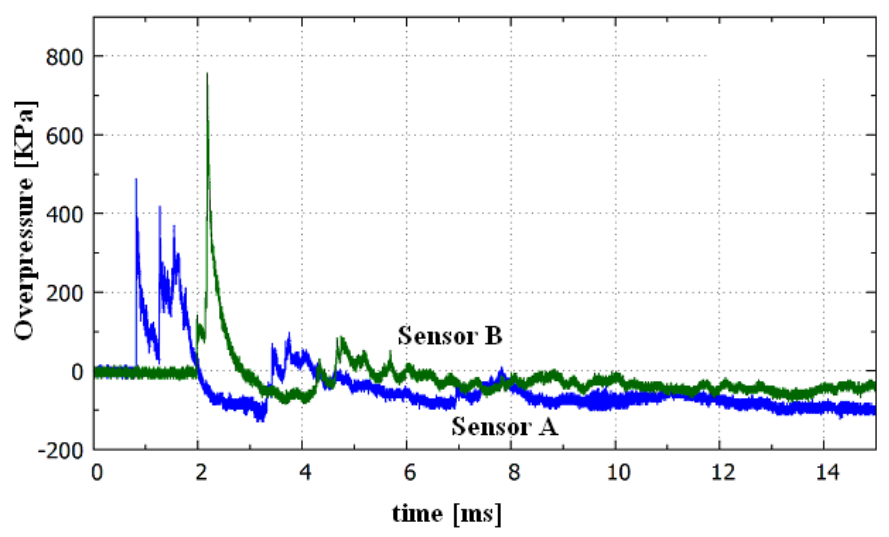

Figure 7: Non-symmetric position of the charge: first shot.

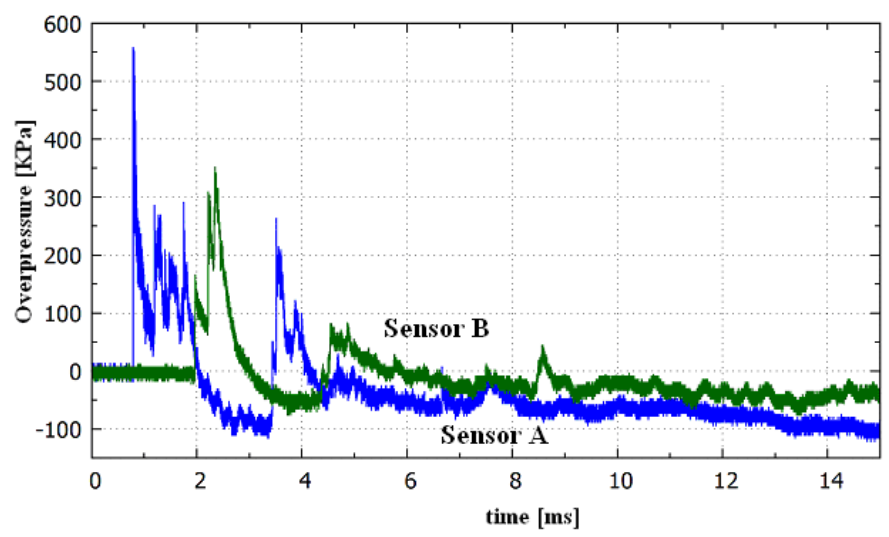

Figure 8: Non-symmetric position of the charge: second shot.

In the given $3 \mathrm{D}$ conditions, the distance between the explosion site and the radius of the spherical wavelength of the shock wave $R$ is expressed by the reduced radius $r$ as:

$$
r=R / \sqrt[3]{m_{x}}
$$

where $m_{x}$ is the mass of the charge. Since the inner radius of the tunnel is $0.5 \mathrm{~m}$ and the nominal mass of the used charges is $0.02 \mathrm{~kg}$ then the reduced distance is:

$\begin{array}{ll}\text { 1st case: } & \text { Sensor A: } r=0.5 \sqrt[3]{0.02}=0.135 \mathrm{~m} . \mathrm{kg}^{1 / 3}, \\ & \text { Sensor B: } r=1.08 \sqrt[3]{0.02}=0.292 \mathrm{~m} \cdot \mathrm{kg}^{1 / 3}, \\ \text { 2nd case: } & \text { Sensor A: } r=0.8 \sqrt[3]{0.02}=0.216 \mathrm{~m} \cdot \mathrm{kg}^{1 / 3}, \\ & \text { Sensor B: } r=1.25 \sqrt[3]{0.02}=0.338 \mathrm{~m} . \mathrm{kg}^{1 / 3} .\end{array}$

The geometric parameters are obtained from Fig. 3 . 
From the above overpressure spectra, the impact time of the shock wave front can be recorded on the inner surface of the tube, the first peak of the positive signal representing the maximum overpressure behind the reflected wave front and the fundamental frequency of the radial component of the oscillation. Higher frequencies are superimposed on the base frequency, which are probably caused by the mutual mechanical interaction between the sensor, its silon sleeve and the body of the tube.

Note that from Fig. 4 in [16] it is seen that the behavior of the shock waves measured at sensor A are really similar for both explosions (Fig. 4 of this paper) but records at sensor B need filtration and probably suffer from some kind of instability.

The model time course of overpressure behind the front of shock wave is, according to [8], shown in Fig. 9.

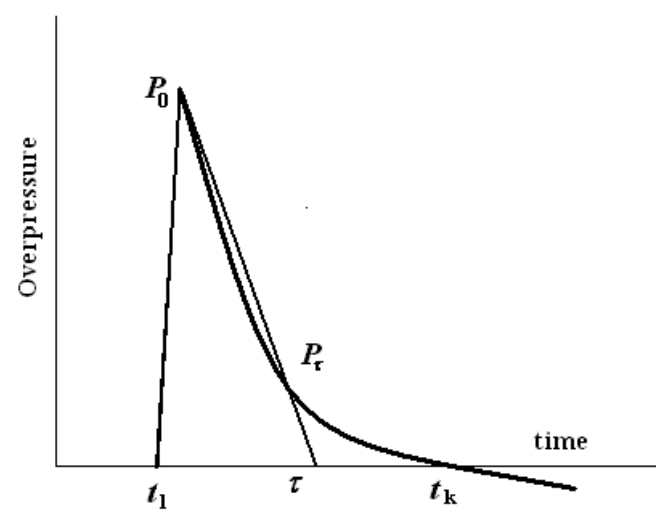

Figure 9: General time course of overpressure.

In what follows, the characteristics follow the recommendations given in [8]. In Fig. 9, the symbols $t_{1}, t_{k}, \tau=\left(t_{k}-t_{1}\right) / 2.2, P_{0}$ and $P_{t} \approx 0.37 P_{0}$ denote successively the moment of explosion, the end of the overpressure phase, the front pressure of the shock wave and the pressure at time $\tau$. In the situation of low values of reduced distance, i.e. $P_{0}>>P_{\text {atmospheric }}$, the influence of the dilute phase on the course of the effects of explosion can be neglected. The time course of the pressure diminution on the wave front within the limits $t_{1} \leq t \leq t_{k}$ generates with sufficient precision an envelope, Fig. 9 , defined by the exponential function

$$
p(t)=\exp (-t / \tau)
$$

In the case of centered position of the charge, the maximum generated overpressures $P_{0}$ were measured at $\mathrm{A}$ in the range of 0.7 to $1.2 \mathrm{MPa}$, giving an average value of $0.92 \mathrm{MPa}$. In the second case they were $500-650 \mathrm{kPa}$ with the average value of $575 \mathrm{kPa}$. The behavior of the shock waves at B was reasonable in the case of the first shot with the maximums $P_{0}$ circa three times lesser. As said above, the second shot cannot be considered as serious enough.

The time, when the pressure phase ends, is denoted as $t_{k}$. It is estimated by the value $0.86 \mathrm{~ms}$. The time from which the overpressure is measured is $t_{1}=0.57 \mathrm{~ms}$. The average of duration of the pressure phase of plain concrete is $0.86-0.57 \mathrm{~ms}=0.29 \mathrm{~ms}$. This values are 
taken from [16]. In the non-symmetric case the average duration of the pressure is $1.1 \mathrm{~ms}$ according to the measurement at $\mathrm{A}$ and $0.9 \mathrm{~ms}$ at $\mathrm{B}$.

The relevant characteristics of measured and calculated values at sensors A and B are listed in Table 1.

Table 1: Relevant characteristics of measured and calculated values at sensors A and B.

\begin{tabular}{|l|c|c|c|}
\hline & $\begin{array}{c}\text { Pressure } \tau \\
(\mathrm{MPa})\end{array}$ & $\begin{array}{c}\text { Higher } \\
\text { frequencies }\end{array}$ & $\begin{array}{c}\text { Lower } \\
\text { frequencies }(\mathrm{Hz})\end{array}$ \\
\hline 1st Case sensor A & 0.34 & 8500 & 2200 \\
\hline 1st Case sensor B & 0.12 & 9000 & 2500 \\
\hline 2nd Case sensor A & 0.21 & 7200 & 1900 \\
\hline 2nd Case sensor B & 0.18 & 7000 & 1800 \\
\hline
\end{tabular}

\section{DISCUSSION OF EXPERIMENTS}

Tests were prepared quite carefully, although some factors may have affected the results. First of all, it is the attachment of sensors to the concrete structure that causes local inhomogeneity in the area of measurement. It is also possible occurrence of instability, caused by various reasons. For example, it is the propagation of gas and other products reflected from the bottom of the tube. At the bottom there was no sense to attach the sensors, due to the placement of the tube on relatively solid bedrock; the interaction with the thill will be minimal. On the other hand, slightly above the tunnel, the largest structural damage occurs, as this part is exposed to the highest pressure. In practice, however, this is a part of the structure of platforms at the metro or walkways in automobile tunnels, where, moreover, the shape of the cut is not completely circular.

In both cases, at the location of the sensors quite standard overpressure distribution over the source of the explosion (sensor A) is registered, corresponding to the exponential course of the overpressure envelopes, see [8] and Fig. 9. This is especially true for the first case (centered location). The overpressure spectrum at the first case of the second charge position is an interesting phenomenon, resulting in a peak pressure of about two times at sensor B than at A. The apparent shock wave interaction is the reason and, moreover, as the same tubes are used for all tests, the measurement results may be affected by the partial local disturbances of the lining.

In this paper the test characteristics are among the most important, but naturally they fulfill not the total set of them. Others, however, can be derived either directly from the abovementioned figures or from norms and recommendations. It is probably mainly important that they can be used to tune the algorithms and inputs to the algorithms for computational programs and also to design and assess real underground structures, which are exposed to possible negative effects of explosion.

\section{ACKNOWLEDGEMENTS}

Financial support by the Grant agency of the Czech Republic No. 17-04204S is greatly acknowledged. The experiments have been carried out at Pardubice, Czech Republic; Assoc/Prof. Pachman was the monitor.

\section{REFERENCES}

[1] Tijsseling, A.S., Fluid-structure interaction in liquid pipe system: A review. J. Fluids Struct., pp. 109-146, 1996. 
[2] Mitu, M., Giurcan, V., Razus, D., Prodan, M. \& Oancea, D., Propagation indices of methane-air explosions in closed vessels. J. Loss Prevent. Process. Ind., 247, pp. 110 119,2017

[3] Mitra, M., Brandes, E. \& Hirsch, W., Mitigation effects on the explosion safety characteristic data of ethanol/air mixtures in closed vessel. Process. Safety Environ. Prot., 117, pp. 190-199, 2018.

[4] Edrl, I., Feldgun, V.R., Karinski, Y.S. \& Yankelevsky, D.Z., On blast pressure analysis due to a partially confined explosion: Afterburning effect. Int. J. Protect. Struct., 3(3), pp. 311-332, 2012.

[5] Cioca, I.L. \& Moraru, R.I., Explosion and/or fire risk assessment methodology: A common approach structured for underground coalmine environments. Archives of Mining Sciences, 57(1), pp. 53-60, 2012.

[6] Haramy, K.Y. \& Brady, B.T., A methodology to determine in situ rock mass failure. Internal Report of Bureau of Mines, Denver, CO, 1995.

[7] Haramy, K.Y., Magers, J.A. \& McDonnel, J.P., Mining under strong roof. 7th International Conference on Ground Control in Mining Nureau of Mines, Denver, USA, pp. 179-194, 1992.

[8] US Army Corps of Engineers ${ }^{\circledR}$, Methodology Manual for the Single-Degree-ofFreedom Blast Effects Design Spreadsheets (SBEDS), PDC TR-06-01 Rev. 1, 2008.

[9] Luccioni, B.M. \& Luege, M., Concrete pavement slab under blast loads. Int. J. Impact. Eng., 32(8), pp. 1248-1266, 2006.

[10] Schenkera, A. et al., Full-scale field tests of concrete slabs subjected to blast loads. Int. J. Impact. Eng., 35(3), pp. 184-198, 2008.

[11] Buchana, P.A. \& Chenb, J.F., Blast resistance of FRP composites and polymer strengthened concrete and masonry structures: A state-of-the-art review. Composites Part B: Engineering, 38(5-6), pp. 509-522, 2007.

[12] De, A., Zimmie, T.F., Abdoun, T. \& Tessari, A., Physical modeling of explosive effects on tunnels. Fourth International Symposium on Tunnel and Safety and Security, Frankfurt am Main, Germany, March 17-19, 2010.

[13] Zhang, P., Wang, J., Qi, S., Li, G., Wang, S. \& Yan, F.. Experimental analysis of the flame speed, brightness and zone thickness of gasoline-air explosion in a closed tunnel. J. Loss Prevent. Process. Ind., 53, pp. 129-135, 2018.

[14] Prochazka, P.P. \& Trckova, J., Stress and deformation states in underground structures using coupled modeling. Acta Geodyn. and Geomat., 5(4), pp. 361-375, 2008.

[15] Bakhtar, K., Impact of joints and discontinuities on the blast-response of responding tunnels studied under physical modeling at 1-g. Int. J. Rock Mech. and Min. Sci., 34(34), $021,1997$.

[16] Prochazka, P. \& Jandekova, D., Measuring overpressure caused by the detonation of explosives in a horizontal tube. ICPS 2019, Poznan, Poland, pp. 23-31, 2019.

[17] Prochazka, P. \& Peskova, S., Modeling the impact of explosions in enclosed spaces using discontinuous boundary elements and finite volume element methods. SUSI, pp. 453-455, 2018.

[18] Prochazka, P.P., Rock bursts due to gas explosion in deep mines based on hexagonal and boundary elements. Adv Eng. Soft., 72, pp. 57-65, 2014.

[19] Prochazka, P.P. \& Lok, T.S., Hereditary problems in long-wall mining by free hexagons. Int. J. Comput. Meth., 8(2), pp. 293-313, 2011. 